\title{
Diabetic Neuropathy Collection: Introduction to Diabetic Neuropathy
}

\author{
Uazman Alam
}

Received: January 21, 2020 / Published online: February 17, 2020

(C) The Author(s) 2020

VG: Victoria Glasson (Managing Editor of Diabetes Therapy).

UA: Uazman Alam (Editorial Board Member of Diabetes Therapy).

This podcast is intended for medical professionals only.

VG: Hello and welcome to the Diabetes Therapy podcast. You are listening to the first podcast in our Diabetic Neuropathy collection. My name is Victoria Glasson and I am the Editor for the journal and today we will be speaking to Dr Uazman Alam, Senior Clinical Lecturer and

Enhanced Digital Features To view enhanced digital features for this article go to https://doi.org/10.6084/ m9.figshare.11672313.

Electronic Supplementary Material The online version of this article (https://doi.org/10.1007/s13300020-00773-6) contains supplementary material, which is available to authorized users.

\section{U. Alam (ه)}

Department of Diabetes and Endocrinology, Liverpool University Hospital NHS Foundation Trust, Liverpool, UK

e-mail: uazman.alam@liverpool.ac.uk

\section{U. Alam}

Department of Eye and Vision Sciences, and the Pain Research Institute, Institute of Ageing and Chronic Disease, University of Liverpool, Liverpool, UK

\section{U. Alam}

Division of Endocrinology, Diabetes and Gastroenterology, University of Manchester, Manchester, UK
Honorary Consultant at Liverpool University Hospital and esteemed member of the Diabetes Therapy Editorial Board.

UA: Thank you Victoria, I'm as you stated, a Senior Clinical Lecturer and Honorary Consultant at Liverpool University Hospital. My background is very much in diabetic neuropathy and lower limb disease in diabetes and I'm really eager to speak about diabetic neuropathy today.

VG: Fantastic, Uazman. Thank you. So to start off, could you please tell us what is diabetic neuropathy?

UA: Sure, so diabetes affects the peripheral nervous system and essentially diabetic neuropathy is a disorder of the peripheral nervous system which occurs due to the underlying diabetes and leads to peripheral nerve dysfunction and it's actually the commonest complication of diabetes. It affects anywhere up to $50 \%$ of people with type 1 and type 2 diabetes $[1,2]$. In fact, looking at the prevalence studies out there, there is even a suggestion that it may affect a lot more [depending on patient population] [3].

VG: What are the signs and symptoms that people should look out for?

UA: So the commonest symptoms tend to be those that are sensory in nature so patients can often complain of pain and can also complain of other kinds of what we call positive symptoms. Those are symptoms of pain and for instance burning; they can complain of 
shooting pain. These are typical positive symptoms. Then we have the negative symptoms which actually tend to be again distributed in the same area which can occur in the glove and stocking distribution in the distal areas in the feet and the hands. The negative symptoms often can be comprised of numbness kind of feelings or sensations [2].

So those are the initial symptoms that people can complain of, but as the disease progresses then you can get what we call motor [system] involvement and that is actually weakness and you can get weakness that occurs in more distal areas [weakness is closely related to signs and severity of diabetic neuropathy]. It occurs more proximally with the progress of time and as symptoms progress [increasing severity]. And on the flip side of this, there is also autonomic symptoms as well and these tend to only present quite late on the disease course. When I mean autonomic symptoms, I mean those that may involve the cardiovascular, gastrointestinal or genitourinary systems and include sweat glands. [Cardiac] Autonomic symptoms tend not to occur in the early stages of autonomic neuropathy [which can be detected by cardiac autonomic testing].

VG: What is the most common type of diabetic neuropathy?

UA: So this would be diabetic peripheral neuropathy, also known as distal symmetrical polyneuropathy. So this is what I mentioned before, the glove and stocking distribution of neuropathy of nerve damage, and this tends to be the commonest form, although autonomic neuropathy is extremely common as well.

VG: How is diabetic neuropathy prevented?

UA: I'm going to have to split this into thinking about diabetic neuropathy in terms of type 1 diabetes and type 2 diabetes. So in type 1 diabetes we have shown that actually having really good glycaemic control can prevent or actually halt the progression of diabetic neuropathy [4], but the jury is somewhat out with type 2 diabetes and a number of studies have actually shown that glucose control by itself may not affect the prevention or the progression of diabetic neuropathy [5]. So in type 2 diabetes we really think of this as a more multifactorial kind of treatment. In general, we should be telling our patients to control the diabetes and try to improve the cardiovascular risk co-factors including the lipids, triglycerides, hypertension [and weight] [6]. There is some data that suggests that if you are heavier you might have more painful symptoms [and is also a risk factor for diabetic neuropathy] [7, 8], so again those individuals with type 2 diabetes is really an improvement in the weight. Again, diet and exercise, avoid excess alcohol, and of course it's really one of the most paramount things we can ask them to do is to stop smoking as well.

VG: Can you take us through the reasons why some people have pain despite a normal examination or no signs of neuropathy?

UA: We need to think about the actual nervous system itself when we think about people who have a normal examination and have no signs of neuropathy but they are still complaining of symptoms and pain, so for instance either burning pain or even numbness. So the peripheral nervous system [grossly] comprises of A-alpha, A-beta and A-delta fibres and also C fibres. And it's the C fibres or what's also known as the smaller [nerve] fibres that are affected first. And these are the ones that are involved in the generation of pain and are related to symptoms including that of burning. So when we think about people who have diabetic neuropathy, it's not just those individuals that have quite severe disease with large [nerve] fibre involvement [and subsequent signs of diabetic neuropathy], but it's those that actually have small fibre deficits so this can actually cause some quite considerable amounts of symptoms and pain despite having a [potentially] normal examination.

VG: So why can diabetic neuropathic pain be worse at night?

UA: Diabetic neuropathy pain is worse at night and this is quite typical of neuropathic pain itself, [including neuropathic pain that can involve (results from) other areas of the somatosensory system]. Why the pain is worse at night still remains relatively unknown although it was first described by Frederick William Pavy in the nineteenth century [9]. There has been some suggestion that there may be involvement in the locus coeruleus which is 
thought to play a part in pain and also sleep, but it remains unknown [in terms of its exact contribution] [10, 11]. What we do know [about the chronobiology of diabetic neuropathy] is that there is increasing pain sensitivity later on in the evening and at night and previous studies have shown this $[12,13]$.

VG: So does this impact on sleep?

UA: It does have an impact on sleep and people can often complain about waking up in the night with painful symptoms and I see this quite often in my clinic. So imagine you're in pain and the pain is worse at the time when you are trying to go to sleep and not only that but it wakes you up at night; this can often be quite debilitating and have a major impact on the quality of life of our patients [14].

VG: Is there a relationship between mood or depression and painful diabetic neuropathy?

UA: Well we just need to think about sleep itself. I've mentioned that sleep can be impaired; if you aren't sleeping very well and you are in chronic pain then you tend to have a worse mood and you are more likely to be depressed. Now unfortunately if you are depressed or have a low mood then you are more likely have painful symptoms. So this can be somewhat of a vicious cycle which, if you can break the cycle then you can get improvements in both the mood and the pain.

There was a study which was published in 2005 by Gore et al. [14] which quite clearly showed that the increasing levels of pain, then the more likely to have anxiety and also depression and the higher levels of these, so really the more pain you are in the more likely people are to have anxiety and depression.

VG: Which autonomic dysfunctions must be managed in patients?

UA: So it's really important for us to understand that autonomic dysfunction can occur relatively early on in the disease course and [in the later stages of the disease] it can have a major impact on the quality of life. So the one major autonomic dysfunction that can occur is erectile dysfunction and it's really important that we ask male patients about erectile dysfunction and this can have a major effect on the quality of life. Also, there's gustatory sweating and there are treatments which are available which are off-label for gustatory sweating. I have used glycopyrrolate paste [15] or solifenacin or even oxybutynin [NICE Evidence Summary-ES10] [16] [all three treatments are off-label for hyperhidrosis] to try and get some improvement in gustatory sweating and it can have a major impact on the quality of life. Imagine if you are going out for a family meal or a meal with friends and as you eat you are profusely sweating. It can have major implications in social exclusion.

VG: Is there a way that we can reverse autonomic neuropathy?

UA: There are some data that suggest that autonomic neuropathy can be reversed in the early stages [17]. Once you have got to orthostatic hypotension or where people are having postural hypertension then it's quite late on in the disease, so then it's not really reversible [18]. But there is some data to suggest that there can be some reversibility particularly with diet and exercise [19]. Unfortunately, we don't have any treatments that affect the pathogenesis of diabetic neuropathy or even autonomic neuropathy.

VG: What happens to the quality of life of the patients [with diabetic neuropathy]?

UA: Well we just need to imagine the various aspects of diabetic neuropathy. So one I've mentioned, pain; the co-morbidities that include anxiety, depression and also lack of sleep or sleep interference. And this would all affect people's quality of life; it can be really quite detrimental.

VG: What kind of information should people suffering with diabetic neuropathy be given?

UA: We should really be educating patients on all aspects of diabetic neuropathy, so this includes the importance of glycaemic control in addition to improving the cardiovascular risk co-factors. In the early stages of diabetes it is really important to try to achieve good control of glycaemia and also to modify any risk factors. Importantly we should be telling people to stop smoking [if they smoke], and if people do have diabetic neuropathy and subsequently have symptoms of pain then they do need to be informed that we are unlikely to achieve 100\% pain relief with any treatment; at best what we are aiming for is $50 \%$ pain relief [20]. But as a 
part of our consultation we should be counselling patients in regards to all of these varying factors.

VG: Is there anything that we can do to prevent neuropathic diabetic foot ulcers?

UA: That's an excellent question. So diabetic neuropathy is the strongest risk factor for foot ulceration and amputation in people with diabetes. As a rule of thumb, those individuals that do have diabetic neuropathy, more so particularly those that have severe neuropathy, need to undergo daily foot examinations. Those that have insensate feet and a lack of sensation really need to emphasize the importance of foot care and protection, i.e. not to walk barefoot. They need to consider how they trim their toenails and to do this with great care and actually have podiatry input for this, and of course think about foot hygiene and look out for any kind of infection in the feet. And again, another really important aspect is the need for wearing wellfitted shoes and not to wear sort of hard-soled shoes where they are walking long distances in this, and of course there is trying to gain advice on footwear early on [21].

VG: What are the main risk factors for developing diabetic neuropathy? Is age a big factor?

UA: So age is a risk factor but that is somewhat in relation to the duration of the diabetes. So the longer the duration of diabetes then the more likely you are to have diabetic complications or diabetic neuropathy. So you can say as a rule of thumb by about 25 years' duration of diabetes, about half of the population will have diabetic neuropathy. There have been other associated factors such as hypertriglyceridemia, hypertension, weight which have all also been linked to diabetic neuropathy.

VG: We are going to be discussing diabetic neuropathy treatments in depth in another podcast but can you quickly talk us through the treatments for different types of neuropathy?

UA: So the mainstay of treatment for all the diabetic neuropathies, whether this is autonomic, distal symmetrical or even if it's another form of diabetic neuropathy, is really try to improve glycaemic control along with the cardiovascular risk factors. Of course, stopping smoking which I have said a number of occasions but that remains really the mainstay of therapy in trying to prevent or trying to halt the progression. Now each individual type of neuropathy will have its own treatment. So for instance diabetic peripheral neuropathy [has specific treatments]. We have talked about pain and we will be talking about pain relief in terms of neuropathic agents, but for instance with autonomic neuropathy we need to consider the various aspects of autonomic neuropathy whether this is cardiac autonomic, whether it's erectile dysfunction or say for instance gastroparesis and we'd treat each of those for symptoms. So erectile dysfunction you can consider phosphodiesterase inhibitors or other kinds of erectile dysfunction measures. Again, testosterone can be low in people with erectile dysfunction, so this may be something that we need to look at on an individual basis particularly people with type 2 diabetes.

Gastroparesis can be quite difficult to treat and there is a number of different therapies that can be used, but these are mainly off-label [domperidone, azithromycin, erythropmycin]. Cardiac autonomic neuropathy again is generally quite asymptomatic in the early stages and only becomes symptomatic later on, but if we are thinking about orthostatic hypotension then there is all the various therapies that are available for the treatment which include fludrocortisone, midodrine and again other offlabel therapies such as pyridostigmine and ephedrine as well as abdominal binders [similar to compression stockings].

VG: Finally, you've mentioned counselling for patients; is this something patients do have access to and that they can utilise?

UA: Sure. So when I say counselling of patient, I mean this is counselling within our own clinics; so this is something that each clinician should be doing. So what are the expectations that each patient has and what are we able to do for the patient in terms of these expectations? We should be counselling patients every time we meet them in clinic, but in terms of formal psychology counselling the access to this can be quite variable actually; so it depends on where you work, particularly in the UK. So I'm quite lucky that we have access to specific pain counsellors and psychologists and 
also diabetes psychologists, and they are really a very helpful resource and should be utilised [when needed]. So I tend to refer people who are having management problems with their diabetes [i.e. significant diabetes distress] and in particular those that are in quite severe pain as well I would refer to the pain psychologist and patients have received quite significant benefits from seeing these individuals [health professionals].

VG: Uazman thank you so much for taking the time to speak to us today. As I mentioned at the start of the podcast we will be releasing another two podcasts in our Diabetic Neuropathy collection focusing on diagnosis, and then another focusing on treatment. Again Uazman, thank you so much.

UA: Thank you, Victoria.

You can listen to more podcasts by subscribing to Adis Rapid+ podcasts with your preferred podcast provider, or by visiting the website. Please note, (parentheses) represent additional information not mentioned in the podcast that has been added into the transcript by the authors for transparency.

\section{ACKNOWLEDGEMENTS}

Funding. No funding or sponsorship was received for this study or publication of this article.

Authorship. All named authors meet the International Committee of Medical Journal Editors (ICMJE) criteria for authorship for this article, take responsibility for the integrity of the work as a whole, and have given their approval for this version to be published.

Disclosures. Uazman Alam has received honoraria for educational meetings from Pfizer and Eli Lilly, is currently a local investigator for BIIB074 (Biogen: NCT03339336) and is a member of the journal's Editorial Board.

Compliance with Ethics Guidelines. This article does not contain any studies with human participants or animals performed by any of the authors.

Peer Review. Please note, contrary to the journal's standard single-blind peer review process, as an editorial this article underwent review by the journal's Editor-in-Chief.

Open Access. This article is distributed under the terms of the Creative Commons Attribution-NonCommercial 4.0 International License (http://creativecommons.org/licenses/ by-nc/4.0/), which permits any noncommercial use, distribution, and reproduction in any medium, provided you give appropriate credit to the original author(s) and the source, provide a link to the Creative Commons license, and indicate if changes were made.

\section{REFERENCES}

1. Young MJ, Boulton AJ, MacLeod AF, Williams DR, Sonksen PH. A multicentre study of the prevalence of diabetic peripheral neuropathy in the United Kingdom hospital clinic population. Diabetologia. 1993;36(2):150-4.

2. Iqbal Z, Azmi S, Yadav R, Ferdousi M, Kumar M, Cuthbertson DJ, et al. Diabetic peripheral neuropathy: epidemiology, diagnosis, and pharmacotherapy. Clin Ther. 2018;40(6):828-49.

3. Lu B, Yang Z, Wang M, et al. High prevalence of diabetic neuropathy in population-based patients diagnosed with type 2 diabetes in the Shanghai downtown. Diabetes Res Clin Pract. 2010;88(3): 289-94.

4. Callaghan BC, Little AA, Feldman EL, Hughes RA. Enhanced glucose control for preventing and treating diabetic neuropathy. Cochrane Database Syst Rev. 2012;6:CD007543.

5. Ang L, Jaiswal M, Martin C, Pop-Busui R. Glucose control and diabetic neuropathy: lessons from recent large clinical trials. Curr Diab Rep. 2014;14(9):528.

6. Gæde P, Lund-Andersen $\mathrm{H}$, Parving $\mathrm{H}-\mathrm{H}$, Pedersen $O$. Effect of a multifactorial intervention on mortality in type 2 diabetes. N Engl J Med. 2008;358(6): 580-91.

7. Callaghan BC, Gao L, Li Y, et al. Diabetes and obesity are the main metabolic drivers of peripheral 
neuropathy. Ann Clin Transl Neurol. 2018;5(4): 397-405.

8. Spallone V, Morganti R, D'Amato C, et al. Clinical correlates of painful diabetic neuropathy and relationship of neuropathic pain with sensorimotor and autonomic nerve function. Eur J Pain. 2011;15(2):153-60.

9. Pavy FW. Introductory address to the discussion on the clinical aspect of glycosuria. Lancet. 1885;126(3249):1033-5.

10. Koh K, Hamada A, Hamada Y, et al. Possible involvement of activated locus coeruleus-noradrenergic neurons in pain-related sleep disorders. Neurosci Lett. 2015;589:200-6.

11. Taylor BK, Westlund KN. The noradrenergic locus coeruleus as a chronic pain generator. J Neurosci Res. 2017;95(6):1336-46.

12. Gilron I. Impact of chronobiology on neuropathic pain treatment. Pain Manag. 2016;6(3):241-7.

13. Odrcich M, Bailey JM, Cahill CM, Gilron I. Chronobiological characteristics of painful diabetic neuropathy and postherpetic neuralgia: diurnal pain variation and effects of analgesic therapy. Pain. 2006;120(1-2):207-12.

14. Gore M, Brandenburg NA, Dukes E, Hoffman DL, Tai KS, Stacey B. Pain severity in diabetic peripheral neuropathy is associated with patient functioning, symptom levels of anxiety and depression, and sleep. J Pain Symptom Manage. 2005;30(4):374-85.

15. Atkin SL, Brown PM. Treatment of diabetic gustatory sweating with topical glycopyrrolate cream. Diabet Med. 1996;13(5):493-4.

16. NICE. Hyperhidrosis: oxybutynin. Evidence summary [ES10]. 2017.

17. Jun JE, Lee S-E, Choi MS, Park SW, Hwang Y-C, Kim $\mathrm{JH}$. Clinical factors associated with the recovery of cardiovascular autonomic neuropathy in patients with type 2 diabetes mellitus. Cardiovasc Diabetol. 2019;18(1):29.

18. Spallone V, Ziegler D, Freeman R, et al. Cardiovascular autonomic neuropathy in diabetes: clinical impact, assessment, diagnosis, and management. Diabetes Metab Res Rev. 2011;27(7):639-53.

19. Costa J, Moreira A, Moreira P, Delgado L, Silva D. Effects of weight changes in the autonomic nervous system: a systematic review and meta-analysis. Clin Nutr. 2019;38(1):110-26.

20. NICE. Neuropathic pain in adults: pharmacological management in non-specialist settings. NICE Clinical Guidence [CG173]. 2013.

21. Boulton AJM. The diabetic foot. Medicine. 2010;38(12):644-8. 